Four alternative schedules of treatment with arsenicals and bismuth are advocated, including an intensive twenty-day course for in patients. In advising the use of intensive arsenical therapy more stress should be laid on the high incidence of the toxic effects of arsenic, which are an unwelcome and important accompaniment.

Arsenical dermatitis and other arsenical toxic effects are well described and illustrated, but in the section on their treatment there is no mention of the use of BAL (di-mercaptopropanol) which has recently superseded all other remedies.

The lesions and pathology of the various stages of syphilis are lucidly described, as also is the Wassermann reaction and its clinical interpretation, The use of the so-called ' provocative 'Wassermann reaction is still advocated although, surely, most authorities have lost faith in this procedure, more especially since a similar 'provocative' effect was demonstrated in non-syphilitic persons by Barnett and others in 1938.

The instructions on the use of bismuth in early syphilis are given in full practical detail but are somewhat marred by the plethora of compounds listed-sixteen in all-without any clear indication of which preparations are favoured or used by the author.

The instructional value of the Handbook, in general, is high, although the text is necessarily compressed. In particular the chapters on congenital syphilis, on vulvovaginitis, and on gonococcal infections of the eye are noteworthy.

The inclusion in future editions of a summary of the present-day public health anti-venereal measures and a brief account of their aims and results would no doubt be welcome to the post-war student, who in many instances is an ex-serviceman with some interest in and knowledge of hygiene.

The Handbook will doubtless retain its position as the most useful small book on this subject for the medical student.

V.E.L.

\section{PENICILLIN IN GENERAL PRACTICE}

By J. L. Hamilton-Paterson, M.D.

(New York, London, and Toronto : Staples Press Ltd. 1947. Second Edit. Pp. 105, with charts and illustrations. Price 5s. net.)

The first edition of this very useful little book was published in 1946, and so rapidly is the field of antibiotics changing its lines of development that already a second edition has appeared, bringing a variety of matters up to date.

There are some useful paragraphs on skin sensitivity and allergic reactions and their significance. Local administration by dressings and ointments and the rather newer use of finely divided sprays (areosols) are more fully discussed. The treatment of subacute bacterial endocarditis is brought up to date, and the chapter covering such miscellaneous conditions as urinary infections, the fevers, puerperal sepsis, and meningitis carries a number of new points. It is interesting to note that nowadays therapeutic concentrations of penicillin can be obtained within the eyeball, apparently without local toxic effect. The chapter on venereal diseases is short but to the point and should remind us of the limitations as well as the success of penicillin in this sphere. On the technical side, only the briefest outline of the older laboratory methods is given ; but in a work of this type more is not necessary. In that a variety of technical modifications are daily being introduced in different laboratories, this section might well have been left out altogether. There is one actual though obviously accidental omission which occurs in the table giving the sensitivity of various organisms tested in vitro, where there is no mention of the gonococcus. However, the omission in no way influences the conclusion that this little book contains a really concise and helpful review of a subject changing so rapidly. The author cannot be expected to do more than, first, carefully catalogue the facts, and then append the latest possibilities and suggestions. These tasks he has done most admirably.

F.A.K.

\section{MONOGRAPHS ON THE PROGRESS OF RESEARCH IN HOLLAND : MODERN DEVELOPMENTS OF CHEMOTHERAPY}

By E. Havinga, H. W. Julius, H. Veldstra, and K. C. Winkler

(Amsterdam : Elsevier Publishing Co., Inc.: London: Cleaver-Hume Press Ltd. 1946. Pp. 175. Price 15s. net.)

No doubt most of us have imagined that under the stress of invasion and the long hard five years of German occupation the tide of medical research in Holland would have remained at low ebb throughout that long period of suffering. It is therefore with some surprise and with much admiration that readers in Great Britain will inspect this sample of the series of monographs on the progress of Dutch research work during the world war 1939-45. Modern Developments of Chemotherapy, one of a series of twelve monographs on scientific subjects, is a slim, attractive volume of 175 pages, excellent as to print and general format. It tells the story in detail of wartime research by Dutch scientists on the mechanism of the action of the sulphonamides, on investigations into the synthesis and activity of new sulphanilamide derivatives, and on pharmacological studies and therapeutic results. Extensive studies are recorded of the physico-chemical characters of the sulphonamides, especially in relation to their antagonism by $p$-aminobenzoic acid and peptone. The methods of investigation included electrometric titrations, the study of ultraviolet absorption spectra, and determinations of surface activity. The behaviour of bacterial cultures in media containing sulphonamides receives detailed and extensive consideration, following which the work of Dutch scientists on the mode of action of these compounds is fully and critically discussed.

Among the many sulphonamide compounds synthesised during the German occupation are eighteen derivatives of pyrimidine, of which six 
are reported to possess an anti-pneumococcal activity in vivo which is equal to or perhaps even stronger than that of sulphapyridine. One of these derivatives, 2-sulphanilylamino 4-methyl pyrimidine (known as percoccide), which will be of particular interest to readers of the Journal, is stated to have given results in the treatment of gonorrhœa which surpass those given by sulphapyridine. It is said that it has the advantage of low toxicity and that its acetyl derivative has a greater. solubility than that of acetyl-sulphapyridine.

The high quality and range of the research work done in a country cut off from all access to the help and stimulus of world literature through five long years will create unbounded admiration in the minds of all of us. The author's modest foreword to the book bears the defiantly appropriate birth-date, "Amsterdam on V.E.Day, 8th May, 1945." V..E. L.

\section{ABSTRACTS}

(The abstracts are divided into the following sections: syphilis (general, therapeutic, pathology); gonorrhaea (general, therapeutic, pathology) ; other venereal disease conditions; public health. After each subsection of abstracts follows a list of articles that have been noted but not abstracted. All subsections will not necessarily be represented in each issue.)

\section{SYPHILIS (GENERAL)}

A Study of Syphilis in a Negro High School in the City of Baltimore, 1939-1943. (1946.) J. vener. Dis. Inform., 27, 200.

This is an analysis of two serological surveys of a negro high school. In each survey one-fourth of those showing positive blood reactions had been known previously to have had syphilis, while $50 \%$ of the syphilis was discovered in students under 15 years of age.

Tables were compiled to assess the probability of acquiring syphilis while at high school. In males no infections occurred between the ages of 11 and 15 years, but by the sixteenth birthday the probability of infection was 9 per 1,000 , and at the age of 20 it had reached 76 per 1,000 . In the females no new infections occurred between 11 and 14 years, but by the fifteenth birthday the probability rate was 24 per 1,000 and by the age of 20 as high as 170 per 1,000 . Previous studies on adult negroes in this area had shown that by the age of 25 nearly $23 \%$ of males and $35 \%$ of females had become infected with syphilis.

R. $\boldsymbol{R}$. Willcox

Asymptomatic Neurosyphilis : Prognosis. HAHN, R. D., and ClaRK, E. G. (1946). Amer. J. Syph., 30, 513.

The prognosis of asymptomatic neurosyphilis, with regard to the eventual state of the spinal fluid and to the clinical outcome, was studied in 533 patients on whom at least two cerebrospinal-fluid examinations had been done, and in 467 patients who had had at least two physical examinations
(271 male and 262 female; 191 white and 342 negro). Only $8.5 \%$ of the patients had received any treatment before the first positive spinal-fluid test. Routine treatment of all cases consisted of trivalent arsenicals and bismuth. Tryparsamide or malarial therapy was also given to a small number of cases.

A large part of the report is devoted to a detailed analysis of the subsequent changes in the spinal fluid in respect of age, race, sex, duration of infection, freatment, initial change in the spinal fluid, and, in particular, the relation of spinal-fluid changes to the clinical outcome. It was noted that the probability of the development of clinical neurosyphilis during the first 10 years of observation was less in the youngest group (under 25 years) than in the other age groups, presumably on account of the shorter duration of the infection. In general the more marked the pathological change in the initial spinal-fluid tests the more unfavourable were the changes in the ultimate spinal-fluid examination and the greater the probability of the onset of manifest neurosyphilis. Spinal fluids, initially of Group I or II, became negative in about half the patients ; whereas, when the initial tests showed the spinal fluid to have been of Group III type, the fluid became negative subsequently in only about a quarter of the patients.

The authors point out that the prognosis in many patients is favourable even when treatment has been totally inadequate. Adequate treatment with trivalent arsenicals and bismuth (40 or more injections of each) was of distinct value in asymptomatic neurosyphilis. No advantage seemed to have accrued from the addition of tryparsamide 